\title{
Research Article \\ Safety Criteria and Standards for Bearing Capacity of Foundation
}

\author{
Yanlong Li, ${ }^{1}$ Wangtao Fan, ${ }^{1}$ Xuguang Chen, ${ }^{2}$ Yunhe Liu, ${ }^{3}$ and Bo Chen ${ }^{4}$ \\ ${ }^{1}$ State Key Laboratory of Eco-Hydraulics in Northwest Arid Region of China, Xi'an University of Technology, Xian 710048, China \\ ${ }^{2}$ College of Engineering, Ocean University of China, Qingdao 266100, China \\ ${ }^{3}$ Institute of Geotechnical Engineering, Xian University of Technology, Xian 710048, China \\ ${ }^{4}$ Shaanxi Water Affair Group Co., Ltd., Xian 710004, China
}

Correspondence should be addressed to Xuguang Chen; chenxuguang1984@ouc.edu.cn

Received 12 August 2017; Revised 2 November 2017; Accepted 21 November 2017; Published 18 December 2017

Academic Editor: Edoardo Artioli

Copyright (c) 2017 Yanlong Li et al. This is an open access article distributed under the Creative Commons Attribution License, which permits unrestricted use, distribution, and reproduction in any medium, provided the original work is properly cited.

\begin{abstract}
This paper focuses on the evaluation standards of factor of safety for foundation stability analysis. The problem of foundation stability is analyzed via the methods of risk analysis of engineering structures and reliability-based design, and the factor of safety for foundation stability is determined by using bearing capacity safety-factor method (BSFM) and strength safety-factor method (SSFM). Based on a typical example, the admissible factors of safety were calibrated with a target reliability index specified in relevant standards. Two safety criteria and their standards of bearing capacity of foundation for these two methods (BSFM and SSFM) were established. The universality of the safety criteria and their standards for foundation reliability was verified based on the concept of the ratio of safety margin (RSM).
\end{abstract}

\section{Introduction}

The stability of foundation is an important factor for foundation design $[1,2]$. In fact, foundation stability is normally evaluated and analyzed via the factor of safety of bearing capacity. Several influence factors for the problem of foundation stability analysis are studied by many researchers [36]. The factor of safety for a foundation can be defined as the ratio between the ultimate bearing capacity and the actual load on the foundation soil. This method relies on the engineering experience and cannot reflect the failure process of the foundation soil mass [7]. However, the strength and safety margin of slopes can be reflected by the calculation method of factor of safety in slope stability analysis and it also has the physical significance. The calculation method and the standard of factor of safety are two important issues for the problems of slope stability analysis and foundation design. Therefore, the standards for factor of safety are the key issue for the foundation and slope stability analysis. These problems can be analyzed via the method of risk analysis for engineering structures and the method of reliabilitybased design. The problem of uncertain slope stability analysis was the first application of reliability-based method in geotechnical engineering [7]. Afterwards, the method of reliability-based analysis was used to analyze the problem of foundation bearing capacity. For example, based on the limit analysis and reliability-based analysis method, Massih analyzed the bearing capacity of strip footings by combining the foundation bearing capacity [8]. Moreover, the method of reliability-based analysis can be combined with numerical method to calculate and analyze the problem of slope stability and foundation bearing capacity. For example, the bearing capacity of a strip footing on undrained clay/weightless soil is analyzed by Griffiths et al. using the reliability-based method and finite-element analysis $[9,10]$. The sensitivity of factor of safety for foundation problem is analyzed by Griffiths using strength reduction method and load increase method [11, 12]. In this study, the admissible range of foundation reliability indexes is investigated through a typical example, and the evaluation standards of the factor of safety are established 
via the bearing capacity safety-factor method (BSFM) and strength safety-factor method (SSFM). The concept of a "ratio of safety margin (RSM)" is used to verify the universality of these standardized values, and the feasibility of RSM was evaluated based on an engineering case study.

\section{Foundation Bearing Capacity Analysis}

2.1. Factor of Safety Method for Foundation Bearing Capacity Analysis. The factor of safety for the problem of foundation stability analysis can be determined via the conventional methods (e.g., limit equilibrium method) and strength reduction method.

2.1.1. Factor of Safety Criteria Based on BSFM. In conventional factor of safety methods, the factor of safety can be defined as the ratio of the ultimate load to the actual load; that is,

$$
F=\frac{q_{f}}{q},
$$

where $F$ is the factor of safety, $q$ is the actual load on the foundation, and $q_{f}$ is the ultimate bearing capacity of the foundation. The value of $q_{f}$ is calculated by using the formula for the bearing capacity of foundation proposed by Terzaghi [13]:

$$
\begin{aligned}
& q_{f}=c N_{c}+\gamma_{1} D N_{q}+0.5 B \gamma_{2} N_{\gamma}, \\
& N_{q}=\tan ^{2}\left(\frac{\pi}{4}+\frac{\varphi}{2}\right) \exp (\pi \tan \varphi), \\
& N_{c}=\frac{\left(N_{q}-1\right)}{\tan \varphi}, \\
& N_{\gamma}=2\left(N_{q}+1\right) \tan \varphi,
\end{aligned}
$$

where $c, \varphi, \gamma_{1}$, and $\gamma_{2}$ are the cohesion, internal friction angle, soil unit weight of footing embedment, and unit weight of the soil beneath the footing, respectively; and $N_{c}, N_{q}$, and $N_{\gamma}$ are the foundation bearing capacity factors.

Meyerhof proposed the formulas of three bearing capacity factors $\left(N_{c}, N_{q}\right.$, and $\left.N_{\gamma}\right)$ for rigid rough and strip footings [14]. The formulas for bearing capacity factor $N_{\gamma}$ developed by Meyerhof and Hansen are also widely used [15-17]. The formulas proposed by Terzaghi, Meyerhof, and Hansen are semiempirical expressions, but the bearing capacity formula of Vesić is more brief and efficient. Thus, Vesićs bearing capacity formula is used to calculate the factor of safety of foundation.

2.1.2. Factor of Safety Criteria Based on SSFM. Foundation can be considered as a slope with zero gradient, and the factor of safety can be calculated using the method of slope stability analysis. Based on this assumption, the corresponding strength indexes are reduced by the reciprocal of $F$ as follows:

$$
\begin{aligned}
c_{e} & =\frac{c}{F}, \\
\varphi_{e} & =\frac{\tan \varphi}{F} .
\end{aligned}
$$

Equations (6) are substituted in (2) to yield

$$
F=\frac{q_{f, e}}{q}
$$

where the subscript $e$ represents the corresponding strength index after reduction.

These two methods (BSFM and SSFM) have different factor of safety definitions, and both of them are used in the deterministic analysis method for factor of safety calculation. The sliding stability analysis of a foundation also can be performed via the uncertain analysis method with the reliability index. Thus, the reliability index of the factor of safety for foundations will be used to analyze the problem of foundation stability in this study.

2.2. Reliability Analysis of Bearing Capacity of Foundation. Based on the limit equilibrium method, the equation for the limit state $g$ can be defined as follows

$$
g=F\left(x_{1}, x_{2}, \ldots, x_{i}\right)-1,
$$

where $x_{i}$ is a group of independent random variables; in this paper, they are the strength parameters $c$ and $\varphi$. The calculation formula of the reliability index $\beta$ is as follows:

$$
\beta=\frac{\mu_{F}-1}{\sigma_{F}},
$$

where $\mu_{F}$ and $\sigma_{F}$ are the mean value and the standard deviation of the factor of safety. The relationship between the factor of safety and reliability index is described by (9), which has been widely used in relevant standards [18, 19]. The reliability index $\beta$ is calculated by the first-order secondmoment method, and a standard dimensionless variable is introduced:

$$
z_{i}=\frac{x_{i}-\mu_{x, i}}{\sigma_{x, i}} .
$$

The reliability index and design points in a plane coordinate space are shown in Figure 1. The origin point $O$ represents the mean value, which is also the most possible value of the random variable. Point $C$ represents the most possible point in a failure state, that is, a design point in the standard space. The length of $O C$ represents the reliability index $\beta$, and the physical significance of $\beta$ is the shortest path that a random variable will travel from the most possible value to the failure surface.

The function can be expanded into a Taylor series at point $C$. Only constant terms and linear terms are reserved 


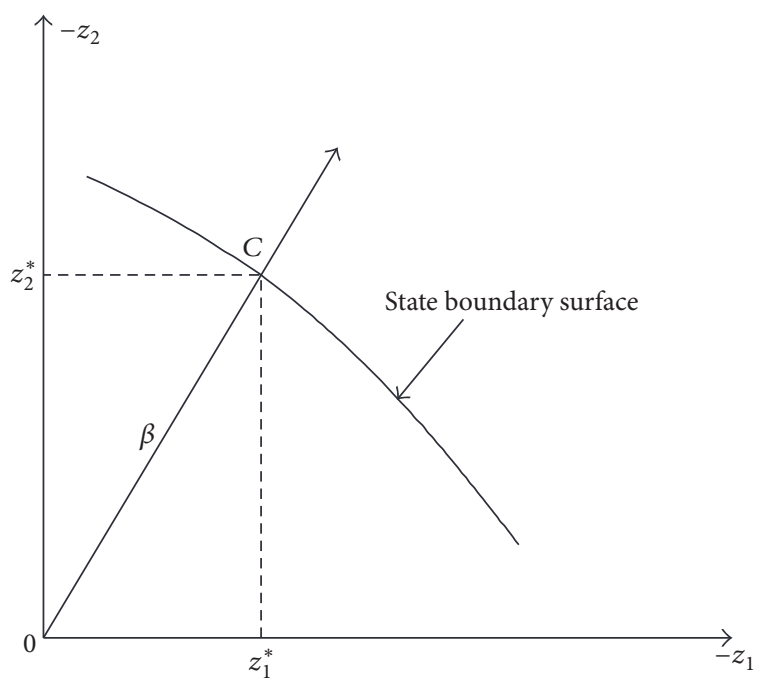

FIGURE 1: Reliability index and design points in a space of reduced variates.

TABLE 1: Admissible reliability indexes specified by the design standard for hydraulic structures in China.

\begin{tabular}{lccc}
\hline & Grade I & Grade II & Grade III \\
\hline Type I failure & 3.7 & 3.2 & 2.7 \\
Type II failure & 4.2 & 3.7 & 3.2 \\
\hline
\end{tabular}

TABLE 2: Variation coefficient statistics of foundation soil strength parameters from literatures.

\begin{tabular}{lcccc}
\hline $\begin{array}{l}\text { Variation } \\
\text { coefficient }\end{array}$ & Meyerhof [15] & Hansen [16] & Vesić [17] & Orr [18] \\
\hline$V_{c}($ for $c)$ & $0.16-0.47$ & $0.14-0.25$ & $0.10-0.35$ & $0.20-0.40$ \\
$V_{\varphi}($ for $\varphi)$ & $0.12-0.37$ & $0.068-0.097$ & $0.02-0.13$ & $0.05-0.15$ \\
\hline
\end{tabular}

to linearize the function. Next, the mean value and standard deviation of the function at point $C$ are calculated; the reliability index $\beta$ is calculated by the following equation:

$$
\beta=\frac{\mu_{g}}{\sigma_{g}}=-\frac{\left.\sum_{i=1}^{n} z_{i}^{*}\left(\partial g / \partial z_{i}\right)\right|_{Z^{*}}}{\sqrt{\sum_{i=1}^{n}\left(\left.\left(\partial g / \partial z_{i}\right)\right|_{Z^{*}}\right)^{2}}} .
$$

The unified design standard for hydraulic engineering in China [20] specifies admissible reliability indexes in hydraulic engineering structures with various safety grades, as shown in Table 1. In this table, type I is a nonsudden failure, and type II is a sudden failure that shows no clear signal before failure but is virtually impossible to remediate or repair afterwards. The failure of a hydraulic engineering structure can be treated as type II failure.

In hydraulic engineering, the consequence of a foundation failure is less serious than that of the significant facilities such as dams. Therefore, the admissible reliability index $\beta_{a}$ is set to 3.7. An important task in reliability analysis is to determine the variation coefficients for the strength indexes. Table 2 lists the variation coefficients of the cohesion $c$ and internal friction angle $\varphi$.

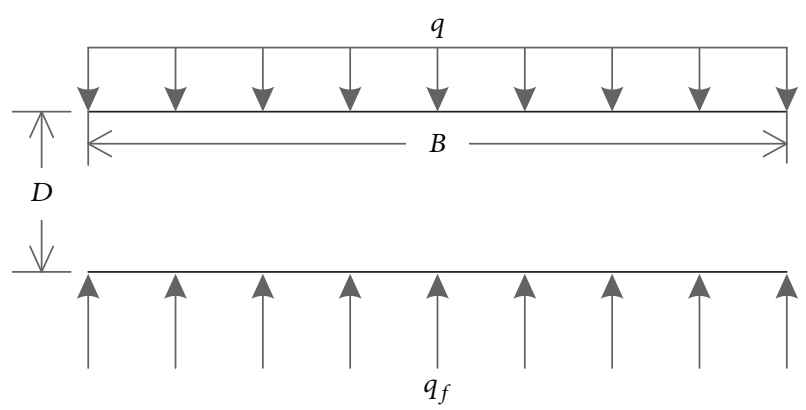

FIGURE 2: Model for analysis of bearing capacity of foundation.

In this study, an example for calculations and analyses is shown in Figure 2. The basic foundation parameters are as follows: the foundation width $B$ is $10 \mathrm{~m}$, the burial depth $D$ is $1.5 \mathrm{~m}$, the unit weight $\gamma_{1}$ is $9 \mathrm{kN} / \mathrm{m}^{3}$, and the soil unit weight $\gamma_{2}$ is $19 \mathrm{kN} / \mathrm{m}^{3}$. The average soil cohesion $\mu_{c}$ is $20 \mathrm{kPa}, \mu_{f}$ is 0.46 , and the actual load $q$ is $600 \mathrm{kN} / \mathrm{m}^{2}$. The strength coefficients are set to design values, which are normally 0.2 quantile design values [19]. The strength parameters are calculated by (12), when the deterministic factor of safety of the foundation is calculated.

$$
x_{k}=\mu_{k}-\sigma_{k} 0.842 \text {, }
$$

where $x_{k}$ represents the soil strength index (cohesion $c$ and internal friction angle $\varphi$ ); the subscript $k$ represents the standard value of each strength index; and $\mu_{k}$ and $\sigma_{k}$ are the average and standard deviation of $x$, respectively.

Based on the two different definitions of factor of safety represented by (1) and (7), the reliability was analyzed, and the factor of safety was calculated by using the first-order second-moment method. The results are presented in Table 3. The values of factor of safety calculated by the two methods (BSFM and SSFM) with different definitions of the factor of safety are significantly different. However, the reliability indexes are very similar, because the two definitions involve the use of the same limit state equation.

\section{Comparison of Foundation Safety Criteria}

The standards for factor of safety of foundations and slopes have slight differences between different countries. Tables 4 and 5 summarize some of these standards.

The comparison of factor of safety for foundation and slope in different countries listed in Tables 4 and 5 indicates that the factor of safety for BSFM which is equal to 2.3 is close to the admissible factor of safety in foundation standards used in China and the United States [21]. In addition, compared with the failure of slopes, the foundation failure has more severe consequences, and it is more reasonable to set the admissible factor of safety to the upper value in Table 5 . Therefore, the factor of safety for SSFM and slope stability analyses which is equal to 1.35 is close to the admissible values in standards used in China and abroad. [19, 22-26]. 
TABLE 3: Factors of safety for the foundation.

\begin{tabular}{|c|c|c|c|c|c|c|c|c|}
\hline \multirow[b]{2}{*}{ Item } & \multicolumn{2}{|c|}{ Strength parameters } & \multirow[b]{2}{*}{$\begin{array}{l}\text { Factors of } \\
\text { safety }\end{array}$} & \multirow[b]{2}{*}{$\begin{array}{l}\text { Mean value } \\
\text { of factors of } \\
\text { safety }\end{array}$} & \multirow[b]{2}{*}{$\begin{array}{l}\text { Standard deviation of } \\
\text { factors of safety }\end{array}$} & \multirow[b]{2}{*}{$\begin{array}{l}\text { Reliability } \\
\text { index }\end{array}$} & \multicolumn{2}{|c|}{ Design point values } \\
\hline & $\begin{array}{l}\text { Cohesion } \\
(\mathrm{kPa})\end{array}$ & $\begin{array}{c}\text { Internal } \\
\text { friction angle } \\
\left(^{\circ}\right)\end{array}$ & & & & & $\begin{array}{l}\text { Cohesion } \\
(\mathrm{kPa})\end{array}$ & $\begin{array}{c}\text { Internal } \\
\text { friction angle } \\
\left(\left(^{\circ}\right)\right.\end{array}$ \\
\hline Symbol & $c$ or $c_{e}$ & $\varphi$ or $\varphi_{e}$ & $F$ & $\mu_{F}$ & $\sigma_{F}$ & $\beta$ & $c^{*}$ & $\varphi^{*}$ \\
\hline BSFM & 16.63 & 24.18 & 2.3 & 3.15 & 0.58 & 3.69 & 15.974 & 0.297 \\
\hline SSFM & 12.23 & 17.76 & 1.35 & 1.50 & 0.14 & 3.69 & 15.974 & 0.297 \\
\hline
\end{tabular}

Note. The subscript $e$ denotes the parameters after strength reduction of the safety factor (corresponding to SSFM).

TABLE 4: Standards for the factors of safety of foundations.

\begin{tabular}{lcc}
\hline Standard & $\begin{array}{c}\text { Admissible factor of } \\
\text { safety }\end{array}$ & Note \\
\hline $\begin{array}{l}\text { Code for Design of Building Foundations } \\
\text { (GB50007-2011) [18] }\end{array}$ & $2.0-3.0$ & Factor for roadway or railway bridge foundations \\
$\begin{array}{l}\text { Engineering and Design-Bearing Capacity of Soils, U.S. } \\
\text { Army Corps of Engineers [21] }\end{array}$ & $2.0-4.0$ & is \\
\hline
\end{tabular}

TABLE 5: Standards for the factors of safety of slopes in China and elsewhere.

\begin{tabular}{lcc}
\hline Standard & $\begin{array}{c}\text { Admissible factor(s) } \\
\text { of safety }\end{array}$ & Note \\
\hline $\begin{array}{l}\text { Design Code for Slopes in Hydraulic Engineering } \\
\text { (SL386-2007) [19] }\end{array}$ & $\begin{array}{c}1.3-1.25,1.25-1.2, \\
1.2-1.15,1.15-1.1\end{array}$ & $\begin{array}{c}\text { Normal condition, correspond to slope grades of 1-4, } \\
\text { respectively }\end{array}$ \\
\hline Canadian Foundation Engineering Manual [22] & $1.3-1.5$ & Following values suggested by Terzaghi and Peck \\
\hline Guide to Slope Maintenance, Hong Kong [23] & $1.2-1.4$ & No \\
\hline
\end{tabular}

\section{Universality Verification}

4.1. Basic Principles. In the example (target reliability index $\beta_{a}$ of 3.7) shown in Figure 2, the values of factor of safety (2.3 and 1.35) which are calculated by BSFM and SSFM, respectively, are defined as the admissible value of the factor of safety $F_{a}$ for a foundation. If the input parameters in this specific example are changed slightly, that is, the foundation width $B$ varies between 8 and $12 \mathrm{~m}$, then the corresponding value of $\beta$ and the factor of safety $F$ also can be calculated via the BSFM and SSFM (shown in Table 3).

The calculated reliability index cannot be 3.7 , and the factor of safety calculated by using BSFM and SSFM cannot be 2.3 and 1.35 , if the foundation width is not equal to $10 \mathrm{~m}$. Then, the question is whether the factor of safety and reliability indexes corresponding to different foundation widths reflect the same level of risk control. Chen et al. [27-29] studied the criteria for analyzing the resistance to sliding of a rockfill dam and a gravity dam. Chen et al. proposed the concept of a RSM and described the relationship between the factor of safety and reliability index. For a factor of safety $F$, the corresponding $\operatorname{RSM} \eta_{F}$ is given by the following equation:

$$
\eta_{F}=\frac{F_{a}}{F}
$$

The reliability analysis requires that the values of $\beta$ be greater than the admissible value $\beta_{a}$ :

$$
\beta \geq \beta_{a} \text {. }
$$

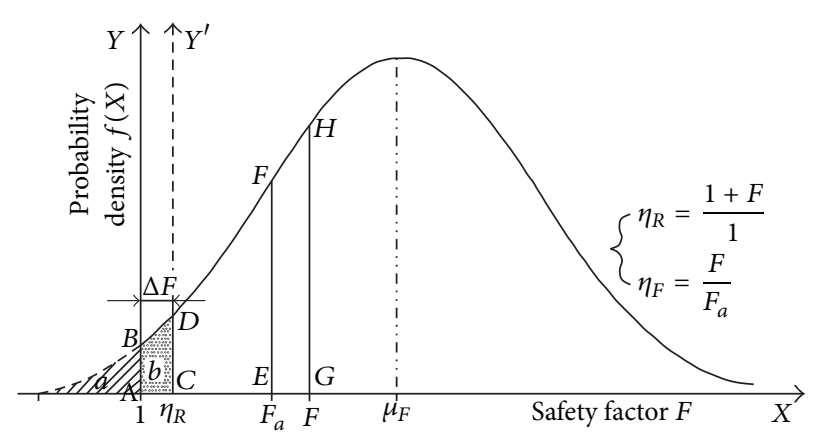

Figure 3: Definition of the equivalent ratio of safety margin obtained using the reliability method.

The area of the shaded region (Figure 3) is lower than the admissible value. The structural failure probability corresponds to $\eta_{F}$ and is not appropriate for formula $\eta_{R}=\beta / \beta_{a}$, because the relationship of $\beta$ with $1-\Phi(\beta)$ has physical significance.

If all safety factors subtract a value $\Delta F$, then a new sample of safety factors $F^{\prime}=F-\Delta F$ is produced which means the Ordinate moved a $\Delta F$ of distance to the right. If the value of $\Delta F$ is assigned like this, it means that the shadow area on the left side of $y$-axis will exactly equal $1-\Phi\left(\beta_{a}\right)$ in the new coordinate system. 
TABLE 6: Results of stability analyses of foundations with various widths $(B)$.

\begin{tabular}{|c|c|c|c|c|c|c|c|}
\hline \multirow{2}{*}{ Symbol } & & \multicolumn{4}{|c|}{ Deterministic model } & \multicolumn{2}{|c|}{ Reliability analysis } \\
\hline & & $\mu_{F}$ & $\sigma_{F}$ & $F$ & $\eta_{F}$ & $\beta$ & $\eta_{R}$ \\
\hline Formula & & (9) & (1) & (1) & $(13)$ & (11) & (19) \\
\hline \multirow{5}{*}{ BSFM, foundation width $B(\mathrm{~m})$} & 8 & 2.73 & 0.53 & 1.99 & 0.865 & 3.28 & 0.909 \\
\hline & 9 & 2.94 & 0.55 & 2.14 & 0.932 & 3.49 & 0.947 \\
\hline & 10 & 3.15 & 0.58 & 2.30 & 0.999 & 3.69 & 0.999 \\
\hline & 11 & 3.36 & 0.61 & 2.45 & 1.065 & 3.86 & 1.061 \\
\hline & 12 & 3.57 & 0.64 & 2.60 & 1.132 & 4.03 & 1.132 \\
\hline \multirow{5}{*}{ SSFM, foundation width $B(\mathrm{~m})$} & 8 & 1.42 & 0.13 & 1.29 & 0.946 & 3.28 & 0.892 \\
\hline & 9 & 1.46 & 0.13 & 1.33 & 0.974 & 3.50 & 0.948 \\
\hline & 10 & 1.50 & 0.14 & 1.35 & 1.002 & 3.69 & 0.999 \\
\hline & 11 & 1.54 & 0.14 & 1.40 & 1.029 & 3.87 & 1.050 \\
\hline & 12 & 1.58 & 0.14 & 1.43 & 1.055 & 4.03 & 1.098 \\
\hline
\end{tabular}

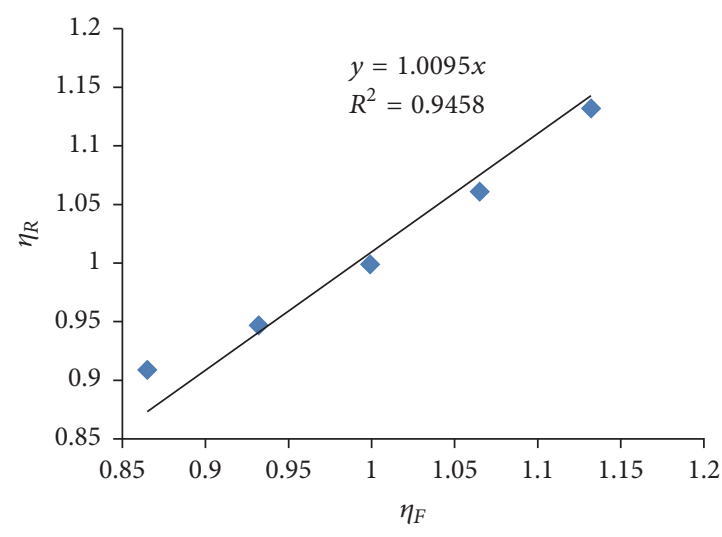

(a) BSFM

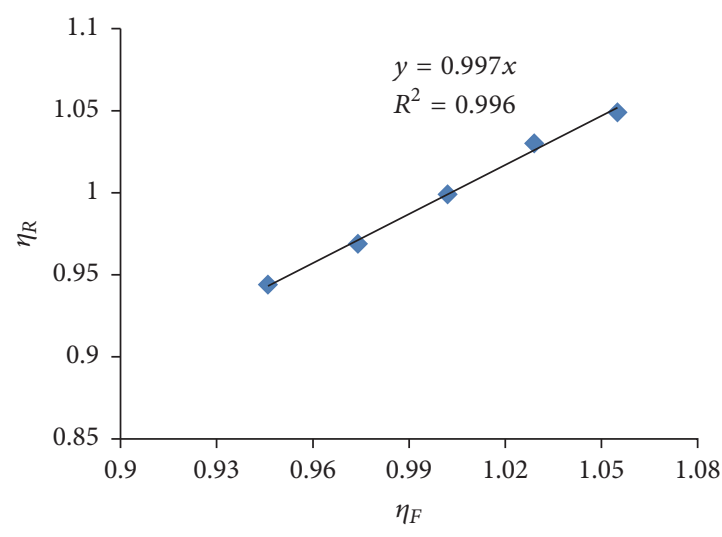

(b) SSFM

FIGURE 4: Linear regressions of RSM for foundations with various widths based on BSFM and SSFM.

In the new sample of safety factors, the mean value is $\mu_{f}-\Delta F$, and the standard deviation does not change. So, the reliability index $\beta^{\prime}$ should be

$$
\beta^{\prime}=\frac{\mu_{F}-1-\Delta F}{\sigma_{F}}=\beta-\frac{\Delta F}{\sigma_{F}},
$$

where $\beta^{\prime}=\beta_{a}$.

$$
\Delta F=\left(\beta-\beta^{\prime}\right) \sigma_{F}=\left(\beta-\beta_{a}\right) \sigma_{F} .
$$

When the structure is in critical state, (17) can be obtained by deterministic and reliability analysis.

$$
\begin{aligned}
F-F_{a} & =0, \\
\Delta F & =0 .
\end{aligned}
$$

Substituting (16) and (17) into (18) gives

$$
\begin{aligned}
\eta_{F}-1 & =0, \\
\left(\beta-\beta_{a}\right) \sigma_{F}+1-1 & =0 .
\end{aligned}
$$

Comparing the two equations, in (19), the RSM $\eta_{R}$ in reliability analysis is defined as follows:

$$
\eta_{R}=\left(\beta-\beta_{a}\right) \sigma_{F}+1 \text {. }
$$

Admissible factor of safety for the slope stability of a rockfill dam and resistance to sliding of a gravity dam have been verified by Chen et al. [27-29]. The results indicate that, under different target operation conditions and methods, the admissible value of factor of safety is quite different, but the RSM always follows $\eta_{R} \approx \eta_{F}$. The RSM $\eta_{F}$ and $\eta_{R}$ calculated based on various foundation widths are listed in Table 6 , and corresponding linear regressions are shown in Figure 4, and the criteria of $\eta_{R} \approx \eta_{F}$ are satisfied.

4.2. Verification of Parameter Universality. The BSFM and SSFM are used to calculate the factor of safety and RSM. The ranges of the parameters are as follows. (1) The unit weight of the soil $\gamma_{2}$ was varied from $17 \mathrm{kN} / \mathrm{m}^{3}$ to $21.5 \mathrm{kN} / \mathrm{m}^{3}$ at increments of $0.5 \mathrm{kN} / \mathrm{m}^{3}$. (2) The internal friction angle $\varphi$ of the fill was varied from 0.385 to 0.610 at increments of 0.025 . (3) The cohesion $c$ was varied from $15 \mathrm{kPa}$ to $24 \mathrm{kPa}$ at increments of $1.0 \mathrm{kPa}$. Regression curves for corresponding RSM $\eta_{F}$ and $\eta_{R}$ are shown in Figure 5. The RSM resulting from the 

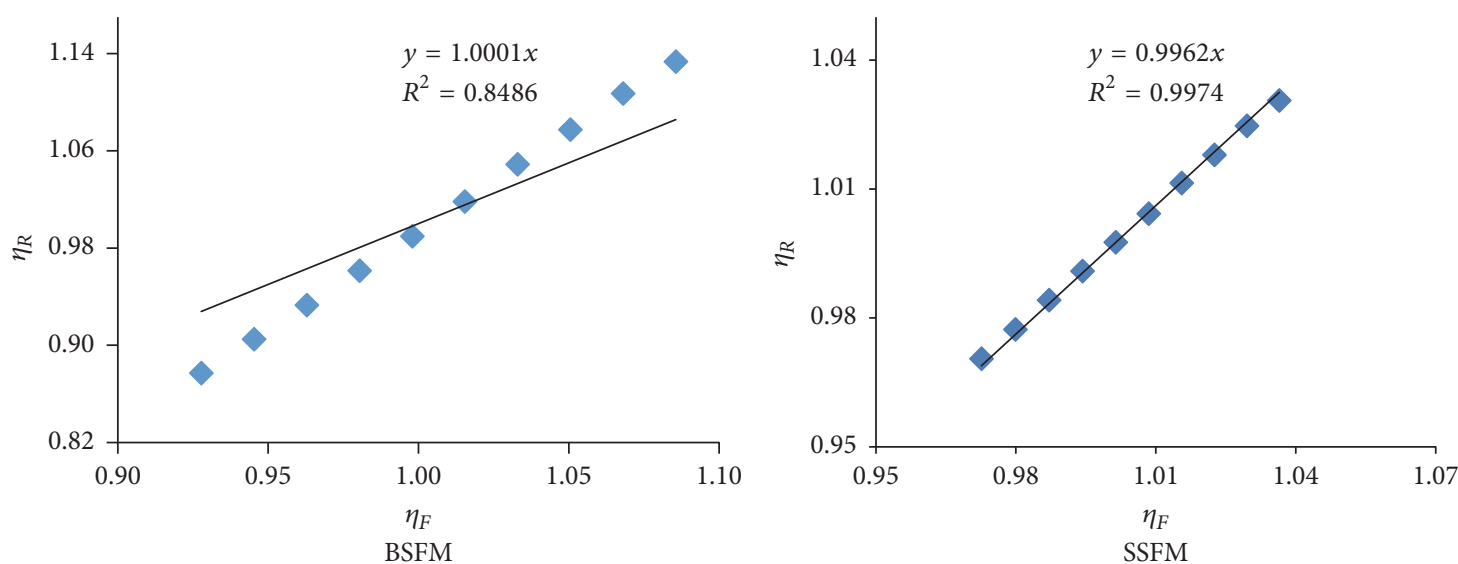

(a) $\eta_{F}-\eta_{R}$ relationships for various soil unit weights
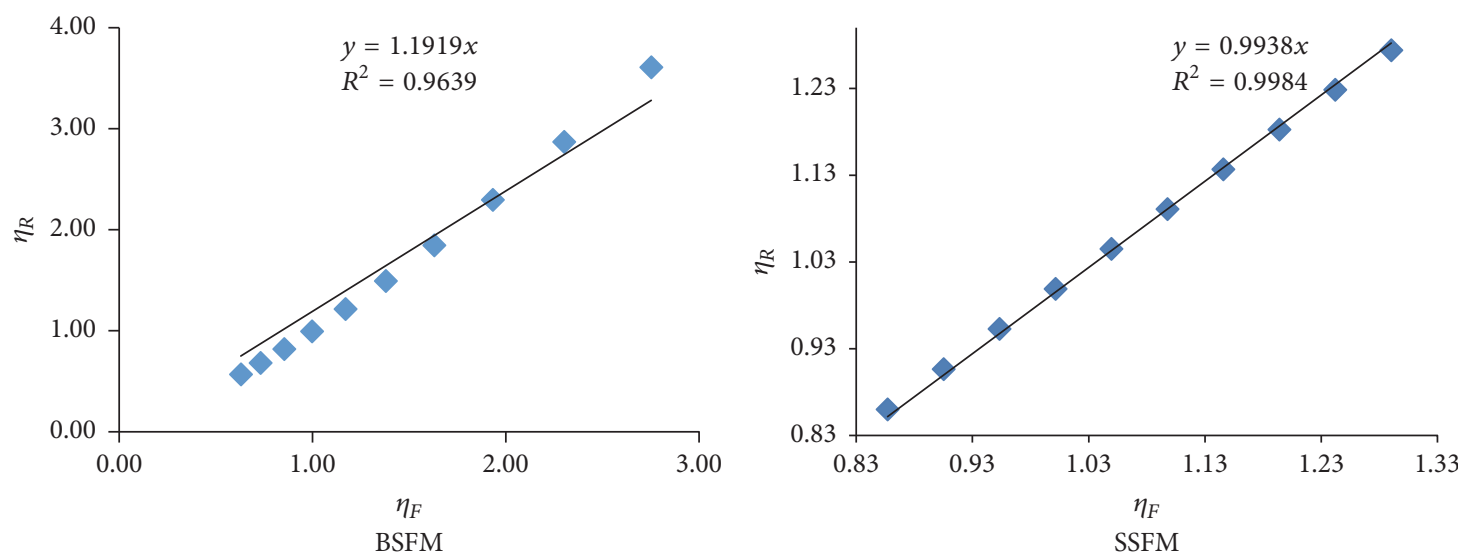

(b) $\eta_{F}-\eta_{R}$ relationship for various soil internal friction angles
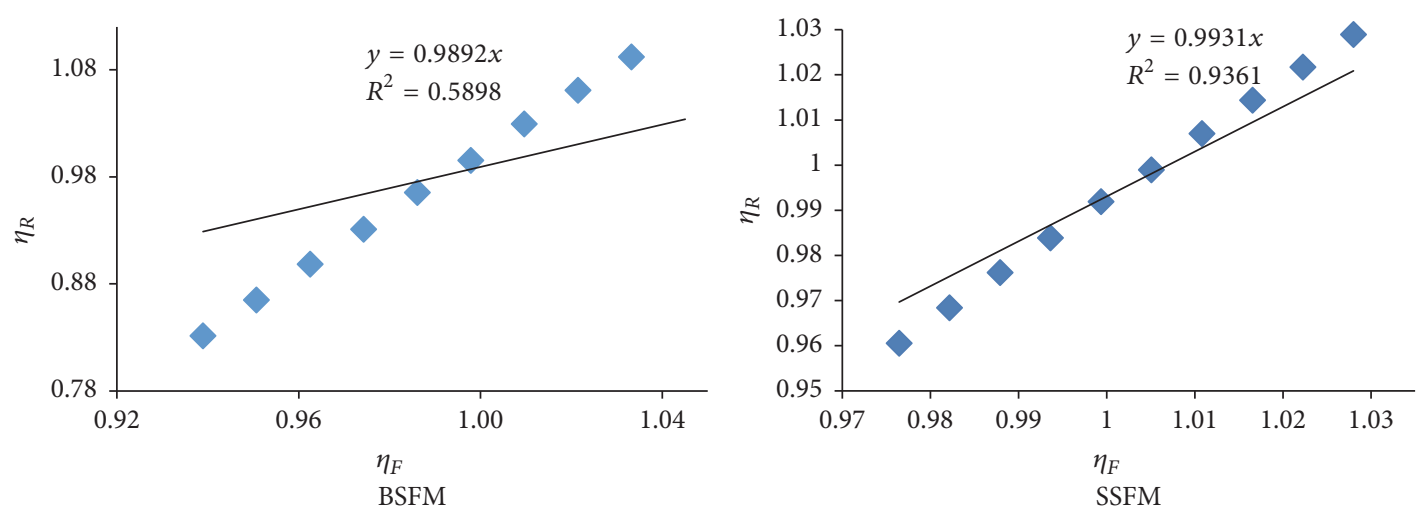

(c) $\eta_{F}-\eta_{R}$ relationships for various value of soil cohesion

FIGURE 5: Investigation of universal applicability of $\eta_{F}-\eta_{R}$ relationships to foundations.

reliability of SSFM is correlated and comparable. However, the correlations of RSM for BSFM are not sufficiently good, especially for the cases of soil unit weight and soil cohesion. The causes of this phenomenon will be investigated in the immediate future.

\section{Case Study}

A foundation from a project has been taken as the engineering case to investigate the feasibility of admissible criteria of the factors of safety [2]. The parameters and dimensions of the footing are shown in Figure 6 . The unit weight of silty clay $\gamma_{1}$ is $18 \mathrm{kN} / \mathrm{m}^{3}$, the unit weight of clay $\gamma_{2}$ is $19.8 \mathrm{kN} / \mathrm{m}^{3}$, the cohesion $c$ is $15 \mathrm{kPa}$, and the internal friction angle $\varphi$ is $25^{\circ}$.

The value of factor of safety for this foundation yield by BSFM (using (1)) follows $F=4.42$. The foundation will satisfy the stability requirement, if the admissible stability factor of safety $F_{a}$ is 2.3 (defined in Section 3), and the RSM $\eta_{F}$ is 1.92. The value of factor of safety for this foundation yield by SSFM (using (7)) follows $F=2.55$. The foundation will 


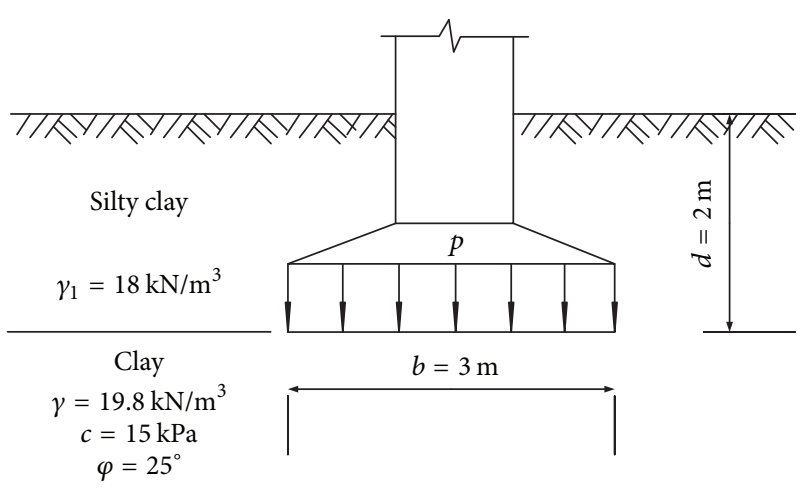

FIgURE 6: Parameters and dimensions of the footing.

satisfy the stability requirement, if the admissible stability factor of safety $F_{a}$ is 1.35 (defined in Section 3), and the RSM $\eta_{F}$ is 1.89. The values of standard deviation of the safety factor $\sigma_{F}=0.26$ and the reliability index $\beta=7.22$ are both yielded by RSM (using (19)). If the admissible reliability index $\beta_{a}$ is 3.7 (defined in Section 2), the RSM $\eta_{R}$ will be 1.90 .

\section{Conclusions}

In this study, the admissible factor of safety was calibrated based primarily on a target reliability index specified in relevant standards. The following conclusions were developed.

(1) Two safety criteria and their standards of bearing capacity of foundation for two methods (BSFM and SSFM) were established. The corresponding factors of safety yield by BSFM and SSFM are 2.3 and 1.35, respectively, if the target reliability index is 3.7 and the variation coefficients for the soil cohesion and internal friction angle are 0.2 and 0.1 . The factor of safety of 2.3 satisfies the admissible factor of safety requirement which is stated in the Code of Design of Building Foundation in China, and the factor of safety of 1.35 slightly exceeded the admissible factor of safety of 1.3 for conventional slopes.

(2) A typical example with different foundation width, strength index, and load was analyzed for discussing the universality of the safety criteria and their standards. The universality of the safety criteria and their standards for foundation reliability was verified using RSM, and the results show that $\eta_{F}$ is equivalent to $\eta_{R}$ under all conditions. Thus, these calibrations have practical value in engineering application.

\section{Conflicts of Interest}

The authors declare that they have no conflicts of interest.

\section{Acknowledgments}

This research is financially supported by the National Science Fund for Outstanding Young Scholars (no. 5172200857), the National Natural Science Foundation of China (no. 51579207), and the innovative research team of Institute of Water Resources and Hydro-Electric Engineering, Xian University of Technology (2016ZZKT-14).

\section{References}

[1] R. Richards, D. G. Elms, and M. Budhu, "Seismic bearing capacity and settlements of foundations," Journal of Geotechnical Engineering, vol. 119, no. 4, pp. 662-674, 1993.

[2] G. H. Qian and Z. Z. Yin, Geotechnical Calculation and Theory, China Water and Power Press, Beijing, China, 1996.

[3] A. S. Azzouz and M. M. Baligh, "Loaded areas on cohesive slopes," Journal of Geotechnical Engineering, vol. 109, no. 5, pp. 724-729, 1983.

[4] Z. G. Xu, Y. Q. Wu, J. Wu, and X. Q. Zhong, "A model of seepage field in the tailings dam considering the chemical clogging process," Advances in Engineering Software, vol. 42, no. 7, pp. 426-434, 2011.

[5] W. Wu, G. Jiang, S. Huang, and C. J. Leo, "Vertical Dynamic Response of Pile Embedded in Layered Transversely Isotropic Soil," Mathematical Problems in Engineering, vol. 2014, Article ID 126916, 12 pages, 2014.

[6] W. B. Wu, H. Liu, M. H. El Naggar, G. X. Mei, and G. S. Jiang, "Torsional dynamic response of a pile embedded in layered soil based on the fictitious soil pile model," Computers \& Geosciences, vol. 80, pp. 190-198, 2016.

[7] B. K. Low, R. B. Gilbert, and S. G. Wright, "Slope reliability analysis using generalized method of slices," Journal of Geotechnical and Geoenvironmental Engineering, vol. 124, no. 4, pp. 350-362, 1998.

[8] D. S. Massih, A.-H. Soubra, and B. K. Low, "ReliabilityBased analysis and design of strip footings against bearing capacity failure," Journal of Geotechnical and Geoenvironmental Engineering, vol. 134, no. 7, pp. 917-928, 2008.

[9] D. V. Griffiths and G. A. Fenton, "Bearing capacity of spatially random soil: the undrained clay Prandtl problem revisited," Géotechnique, vol. 51, no. 4, pp. 351-359, 2001.

[10] A. M. Hasofer and N. C. Lind, "Exact and invariant secondmoment code format," Journal of the Engineering Mechanics Division, vol. 100, pp. 111-121, 1974.

[11] D. V. Griffiths, "Observations on load and strength factors in bearing capacity analysis," Journal of Geotechnical and Geoenvironmental Engineering, vol. 141, no. 7, Article ID 06015004, 2015.

[12] D. V. Griffiths, "A note on load and resistance factors in slopes and foundations," in Proceedings of the XV Geotechnical Colombian Congress and II International Specialized Conference on Soft Rocks, 2016.

[13] K. Terzaghi, Theoretical Soil Mechanics, John Wiley and Sons, New York, NY, USA, 1943.

[14] G. G. Meyerhof, "The ultimate bearing capacity of foundations," Géotechnique, vol. 2, no. 4, pp. 301-332, 1951.

[15] G. G. Meyerhof, "Some recent research on the bearing capacity of foundations," Canadian Geotechnical Journal, vol. 1, no. 1, pp. 16-26, 1963.

[16] J. B. Hansen, "A revised and extended formula for bearing capacity, Danish Geotechnical Institute Bulletin, vol. 28, pp. 5-11, 1968.

[17] A. S. Vesić, "Analysis of ultimate loads of shallow foundations," Journal of the Soil Mechanics and Foundations Division ASCE, vol. 99, no. 1, pp. 45-73, 1973.

[18] Code for design of building foundation (GB 50007-2011), China Architecture and Building Press, Beijing, China, 2012.

[19] Design code for slopes in hydraulic engineering (SL/386-2007), Beijing, China Water Power Press, Beijing, China, 2007. 
[20] Unified standard for reliability design of hydraulic and Hydropower Engineering Structures. (GB50199-2013), China Planning Press, Beijing, China, 2014.

[21] Engineering and Design-Bearing Capacity of Soils. U.S. Army Corps of Engineers, Washington, DC.20314-10000.

[22] Canadian Foundation Engineering Manual, Canadian Geotechnical Society Foundations Committee, BiTech Publisher Ltd, Richmond, Canada, 4th edition, 2006.

[23] Geoguide 5: Guide to Slope Maintenance, The Hong Kong Geotechnical Engineering Office, Government Publications Centre, Hong Kong, Hong Kong, 2003.

[24] Building code requirements for structural concrete, American Certification Institute, 1992.

[25] The European standard. Eurocode 7: Geotechnical design, The authority of the Standards Policy and Strategy Committee, 2004.

[26] Guides for building foundation structure design, Architectural Institute of Japan, 1988.

[27] Z. Y. Chen, L. H. Chen, J. C. Xu et al., "Quantitative deterministic versus probability analyses based on a safety margin criterion," Science China Technological Sciences, vol. 57, no. 10, pp. 1988-2000, 2014.

[28] Z. Y. Chen, J. C. Xu, P. Sun, C. Wu, Y. J. Wang, and L. H. Chen, "Reliability analysis on sliding stability of gravity dams: part I, an approach using criterion of safety margin ratio," Journal of Hydroelectric Power, vol. 31, no. 3, pp. 167-178, 2012 (Chinese).

[29] Z. Y. Chen, J. C. Xu, L. H. Chen, Y. J. Wang, P. Sun, and C. Wu, "Reliability analysis on sliding stability of gravity dams: part II: determination of shear strength parameters and partial factors," Journal of Hydroelectric Engineering, vol. 31, no. 3, pp. 160-167, 2012 (Chinese). 


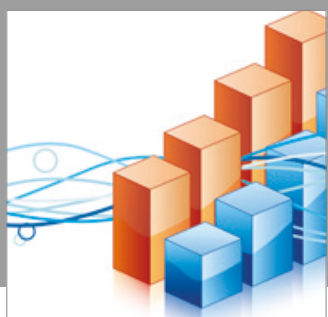

Advances in

Operations Research

vatersals

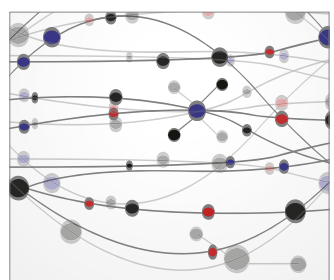

\section{The Scientific} World Journal
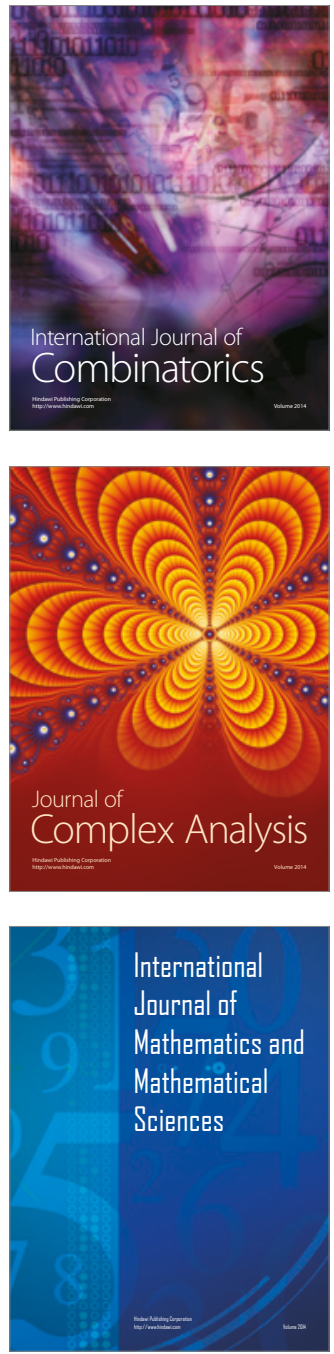
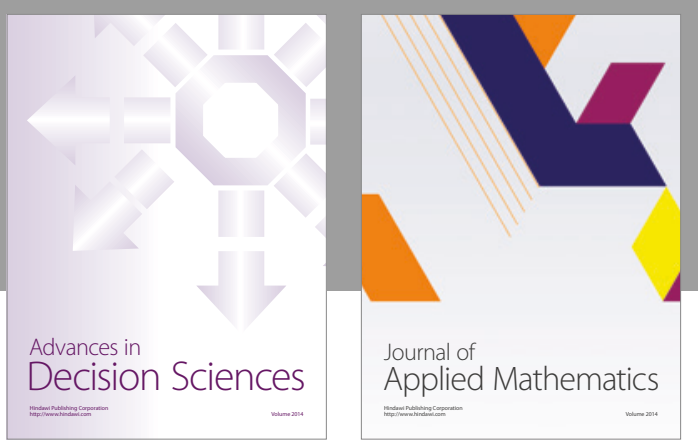

Algebra

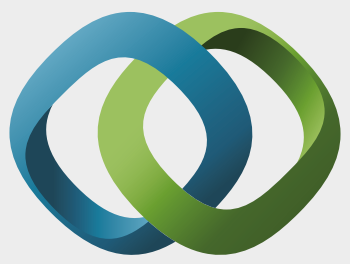

\section{Hindawi}

Submit your manuscripts at

https://www.hindawi.com
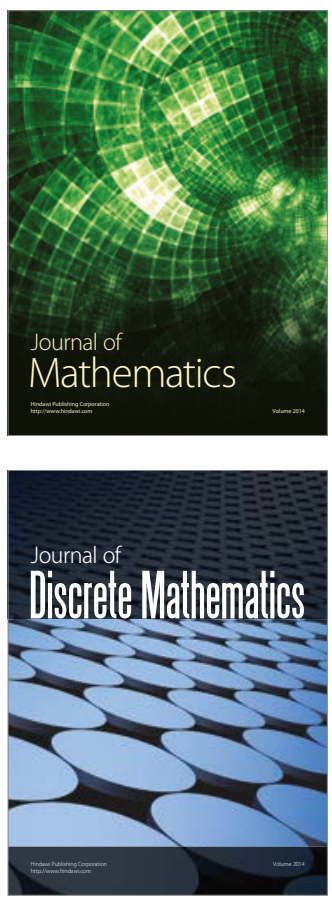

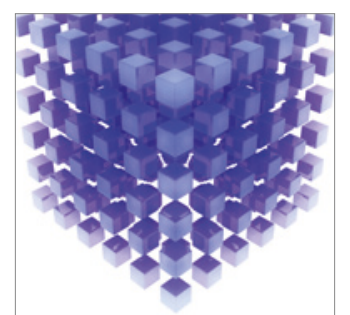

Mathematical Problems in Engineering
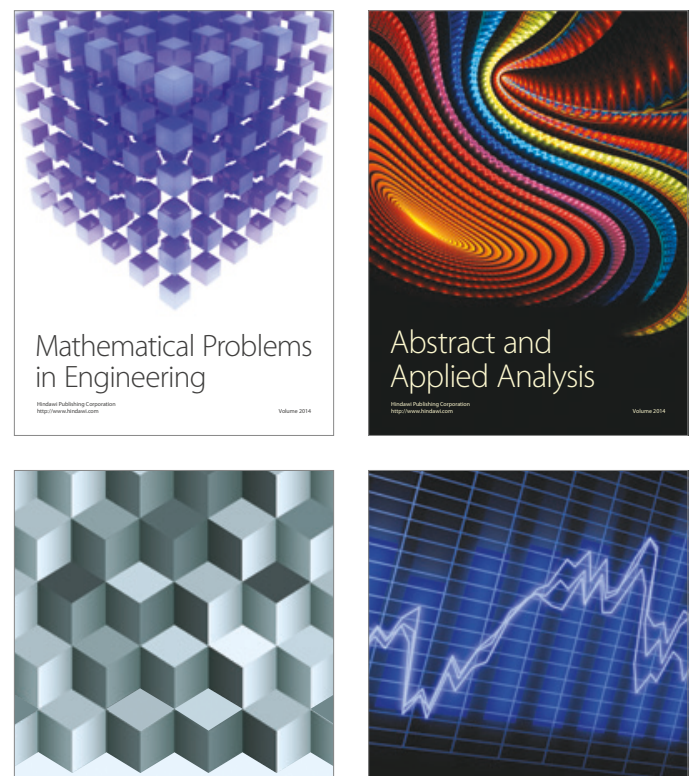

Journal of

Function Spaces

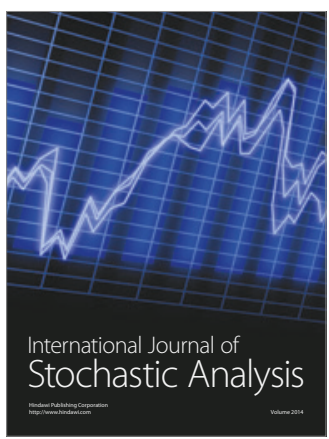

Probability and Statistics
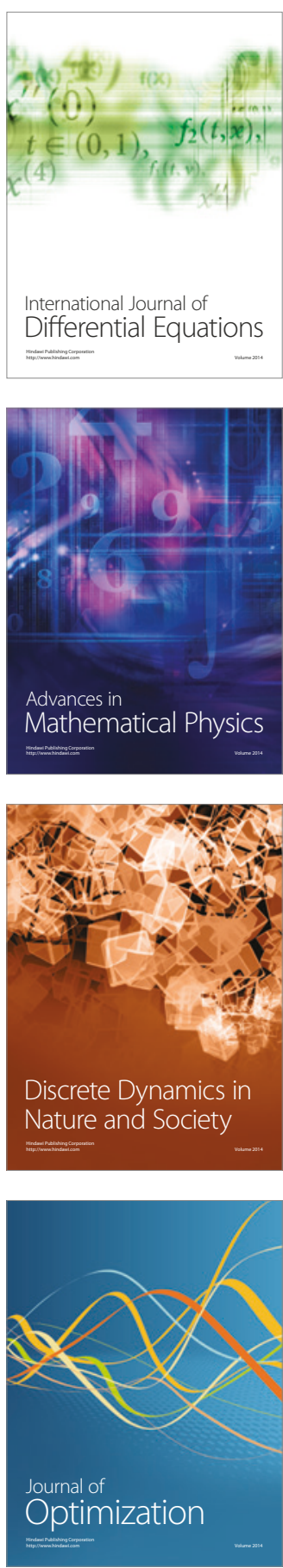